\title{
A arte visual no mundo contemporâneo ${ }^{1}$
}

Nelcí Andreatta Kunzler ${ }^{2}$

\section{Resumo}

O mundo contemporâneo é multifacetado, complexo e polêmico. Alguns teóricos o denominam de Pós-Modernidade, outros de Modernidade tardia, outros ainda, de Neomodernidade. Na arte, como em outros campos, já se fala em Hipermodernidade. Alguns ainda acreditam que estamos em plena Modernidade. São diversos os estudos acerca das denominações do momento atual. É em meio a essa pluralidade de posturas, idéias e fatos que o mundo contemporâneo está se constituindo e nele está inserido o(a) artista e a arte. Neste texto, visamos fazer um recorte, especificamente, da arte visual contemporânea vinculada ao contexto atual e como algumas questões mais amplas do mundo contemporâneo aparecem nas características da arte; como os pensamentos atuais refletem e interferem no processo de criação e de fruição artística. As características e pensamentos atuais que abordamos ao contextualizar a arte no mundo atual são: a dissolução das grandes narrativas; a cultura; a identidade; a inclusão das diferenças; a globalização; a fragmentação e a efemeridade.

Palavras-chave: contemporaneidade, arte visual contemporânea, pluralidade.

\section{Abstract}

The contemporary world is multifaceted, complex and controversial. Some theorists call it Post-Modernity, other ones as late Modernity, and even others as Neo-Modernity. In art, like in other fields, there is already talking about Hypermodernity. Some still believe that we are in full Modernity. There are several studies about the names used currently. It is amid this plurality of positions, ideas and facts that the contemporary world is being constituted, and the artist and the art are inserted in it. In this paper, we aim to make a cut, specifically of the contemporary visual art linked to the current context and how some broader issues in the contemporary world appear in the characteristics of art, such as current thoughts reflect and interfere in the process of artistic creation and enjoyment.

\footnotetext{
${ }^{1}$ O presente artigo parte da dissertação intitulada "O ensino da arte visual contemporânea e a formação do(a) professor(a) de arte: análise de uma experiência desenvolvida nas escolas de Jóia" defendida em 27/09/05, sob a orientação da Profa. Claudia Luiza Caimi, Doutora em Teoria da Literatura pela PUC/RS.

2 Graduada em Educação Artística - Habilitação Artes Plásticas, Especialista em Metodologia do Ensino das Artes e Mestre em Educação nas Ciências, pela UNIJUÍ- Universidade Regional do Estado do Rio Grande do Sul. É professora efetiva da rede estadual de ensino do estado do RS. Atualmente trabalha no Setor Pedagógico da 36a Coordenadoria Regional de Educação, de Ijuí, atuando na formação continuada de professores de arte da região de abrangência da 36a CRE e na organização de eventos culturais e artísticos.
} 
The characteristics and current thoughts that we address when contextualizing the art in the world today are: the dissolution of large narratives; the culture; the identity; the inclusion of the differences; the globalization; the fragmentation and the ephemerality.

Keywords: contemporaneity, contemporary visual art, plurality.

As obras de arte são criadas a partir do diálogo e da vivência do artista com o contexto social, político, econômico, filosófico, em que está inserido. Sendo assim, características que se fazem presentes no mundo contemporâneo refletem na arte, seja na postura do artista, no conceito da arte e/ou nas características apresentadas nas diferentes linguagens artísticas. Compreender a arte visual contemporânea, assim como qualquer arte requer entendê-la vinculada ao contexto atual, buscando situar como questões mais amplas que envolvem o mundo contemporâneo nela se apresenta. Para isso, buscamos fazer relações com as seguintes discussões e a arte: a dissolução das grandes narrativas; a cultura; a identidade; a inclusão das diferenças; a globalização; a fragmentação e a efemeridade, numa tentativa de ampliar repertórios e aproximar os leitores de uma maior compreensão da arte de hoje.

A arte contemporânea, assim como as obras de outros tempos, busca sentido. E o espectador também. O que ocorre é que muitas vezes os espectadores não compreendem as manifestações a que estão expostos, o que os leva a duvidar de sua legitimidade. "Mas por quê? Será que a arte de hoje não consegue sensibilizar o público? Ou será que é ele que não está suficientemente aberto ou preparado para lidar com essa produção?" (ALBUQUERQUE, 2005a, p. 14). Essa sensação de incompreensão e de dúvida do que é arte, não é tão recente assim. Em outros tempos também acontecia esse estranhamento.

Engana-se quem pensa que este estranhamento é privilégio dos dias atuais. A história da arte é marcada por incompreensões. Van Gogh vendeu um único quadro em toda a sua vida. Proust teve sua obra-prima recusada por várias editoras. Cézanne foi rechaçado pela própria família [...] (ALBUQUERQUE, 2005a, p. 15).

Para Agnaldo Farias, citado por ALBUQUERQUE (2005a, p.15), a incompreensão do público leva muitas vezes à rejeição e se torna atitude de defesa do espectador, uma vez que "a arte de hoje tira o chão da gente. Propõe novas formas de se olhar as mesmas coisas. Daí o sentimento de aversão: algo que eu não compreendo é algo que afirma a minha impotência".

Entender a arte contemporânea requer saber também o que significa ser contemporâneo em arte. Nem tudo que se produz em arte hoje pode ser classificado enquanto arte 
contemporânea. Agnaldo Farias diz em entrevista a Albuquerque que o termo não designa uma questão temporal.

Eu cobro da arte que ela me inquiete. Isso poderia ser uma definição: contemporâneos são os trabalhos que não são acomodados. Dentro dessa lógica, Goya é profundamente contemporâneo. Continua difícil olhar uma obra dele. Ficar diante de um Velázquez não é mole. [...] Há obras que perduram, não perdem o vigor. [...]Por isso eu diria que nem tudo que é feito agora é arte contemporânea, mas nem tudo o que foi feito anteriormente é arte do passado" (ALBUQUERQUE, 2005a, p.14).

O que nos falta, talvez, seja compreender também um pouco mais sobre o mundo em que este artista está inserido e como as idéias e pensamentos deste mundo vão modificando-se e interferindo na arte.

A partir da segunda metade do século $X X$, o mundo foi marcado por mudanças importantes nos mais diferentes segmentos da sociedade. Com a $1^{\text {a }}$ e a $2^{\text {a }}$ Guerra Mundial, o mundo revê sua caminhada e a crença na ciência começa a ser abalada. Santos (2004, p. 20), que defende a possibilidade de vivermos um momento pósmoderno, diz que

simbolicamente o Pós-Modernismo nasceu às 8 horas e 15 minutos do dia 6 de agosto de 1945, quando a bomba atômica fez 'booom' sobre Hiroshima. Ali a modernidade - equivalente à civilização industrial - encerrou seu capítulo no livro da História, ao superar seu poder criador pela sua força destruidora.

Isso abala a crença na ciência, visto que a sua força foi usada para a destruição da humanidade. O progresso técnico-científico não trouxe a felicidade desejada a uma grande parcela da população como se acreditava.

Com esses acontecimentos, o pensamento moderno toma variados rumos. O período pós-guerra traz novas reflexões e mudanças de postura frente à vida, ao conhecimento, à razão.

No contexto da arte, Duchamp foi o mais radical, que com seus ready-made ${ }^{3}$, ousou criticar e questionar a arte e seu papel. A arte artesanal, para Duchamp e os dadaístas, estava morta, ao mesmo tempo em que não se acreditava que a industrialização e a vida moderna pudessem aliar-se à arte ou vice-versa. Os ready-made dispensaram o artesanato e não se aderiram às técnicas industriais. Essa ruptura provocou uma série de discussões acerca da arte: Quem é o artista? O que é a arte? Quais os rumos que ela

\footnotetext{
${ }^{3}$ ready-made: nome dado por Marcel Duchamp a artigos e objetos produzido em massa, selecionado ao acaso pelo artista e exposto como obra de arte. Esses objetos é um entre uma série de outros idênticos, sem individualidade ou características próprias.
} 
deve tomar? Quem decide o que e quando é arte? Essa atitude de Duchamp abriu caminhos a outras manifestações e conceitos da arte, redefinindo suas características.

Mais tarde, na década de 60, a arte amplia-se ainda mais e seus conceitos variam, outras linguagens e outras formas de representação são abordadas pelos artistas (provocados a partir das idéias de Duchamp e os dadaístas, e também dos cubistas no início do século $X X)$. Deste período em diante, a arte, considerada para alguns autores como pósmoderna, para outros como um desdobramento e amadurecimento do Modernismo, rompeu limites e tornou-se eclética.

A pintura não morreu, tampouco a escultura. Juntaram-se a elas instalações, objetos, textos, Internet e outros meios. Um elenco complexo e sofisticado de suportes e possibilidades matéricas se abre naturalmente aos artistas, que substituem essa preocupação com o meio por uma outra, ligada ao sentido. Artistas contemporâneos buscam sentido. Um sentido que pode estar alicerçado nas preocupações formais que são intrínsecas à arte e que se sofisticaram no desenvolvimento dos projetos modernistas do século 20, mas que finca seus valores na compreensão (e apreensão) da realidade, infiltrada dos meandros da política, da economia, da ecologia, da educação, da cultura, da fantasia, da afetividade (CANTON, 2001, p. 30).

E essa arte é eclética em muitos de seus aspectos: não só na linguagem, mas também no suporte, nos materiais, no conceito, na relação com o espectador. Eclética tanto quanto o mundo em que vivemos.

O momento atual apresenta muitas facetas, é plural e transitório em pensamentos, posturas, ações e acontecimentos. Para melhor compreendê-lo, temos que entendê-lo cheio de contradições, como nos apresenta BERMAN:

O turbilhão da vida moderna tem sido alimentado por muitas fontes: grandes descobertas nas ciências físicas, com a mudança da nossa imagem do universo e do lugar que ocupamos nele; a industrialização de produção, que transforma conhecimento científico em tecnologia, cria novos ambientes humanos e destrói os antigos, acelera o próprio ritmo de vida, gera novas formas de poder corporativo e de luta de classes; descomunal explosão demográfica, que penaliza milhões de pessoas arrancadas de seu habitat ancestral, empurrando-as pelos caminhos do mundo em direção a novas vidas; rápido e muitas vezes catastrófico crescimento urbano; sistemas de comunicação de massa, dinâmicos em seu desenvolvimento, que embrulham e amarram, no mesmo pacote, os mais variados indivíduos e sociedades; $(. .$. um mercado capitalista mundial, drasticamente flutuante, em permanente expansão. (1997, p. 16).

O mundo também modificou-se rapidamente devido ao processo de globalização pois atualmente este se tornou bem mais acelerado e intensificado pelas novas tecnologias. 
Primeiro veio a TV, depois a informática, que alteram de maneira intensa e profunda o modo das relações afetivas, cognitivas e sensíveis das pessoas, uma vez que se acentua a relação virtual com o mundo, limitando a experiência vivenciada diretamente.

A globalização se refere àqueles processos, atuantes numa escala global, que atravessam fronteiras nacionais, integrando e conectando comunidades e organizações em novas combinações de espaço-tempo, tornando o mundo, em realidade e experiência, mais interconectado (HALL, 2003, p. 67).

Globalização também implica uniformização, troca e reconhecimento de padrões econômicos e culturais em âmbito mundial, dada a rapidez e a facilidade de comunicação nos tempos atuais. Enquanto no passado os instrumentos da integração foram a caravela, o barco à vela, o barco a vapor e o trem, seguidos do telégrafo e do telefone, a globalização recente faz-se pelos satélites e pelos computadores ligados à Internet. Tais meios geram grandes mudanças no sentido de produzir novas identidades sociais e individuais.

Segundo alguns autores, estamos na era pós-industrial e na era da informação, o que modifica bastante o modo de vida em que estamos inseridos. A denominação de sociedade da informação serve para designar este mundo mediatizado em que hoje vivemos. A percepção que temos hoje do mundo modificou-se devido aos complexos e constantes dispositivos de mediatização que marcam e modificam o ritmo da nossa vida cotidiana, interferindo cada vez mais não só a nossa percepção imediata do mundo, mas também na nossa experiência individual e coletiva.

Heartney apresenta algumas situações "pós-modernas" para caracterizar o período de hoje como Pós-modernidade.

Considerem, por exemplo, a exclusão da imprensa das cenas reais de carnificina durante a Guerra do Golfo de 1991. No lugar delas, foi mostrada uma gravação, realizada pela aeronáutica, do visor do equipamento de tiro dos aviões. Isso resultou em uma guerra que acabou na tela da televisão como um videogame de golpes cirúrgicos em alvos abstratos, bidimensionais. (HEARTNEY, 2002, p. 7).

Com esse exemplo marca-se uma forte característica pós-moderna por sua remoção de uma realidade, cuja ausência nem mesmo é sentida. "A nossa compreensão do mundo é baseada, antes de mais nada, nas imagens mediadas." (HEARTNEY, 2002, p. 7).

Para Pereira, que designa o período atual de Pós-Modernidade, o processo iniciado com os movimentos culturais da década de 60 tornou-se ponto culminante que discutiu 
questões em relação ao pensamento anterior e provocando mudanças no pensamento moderno, chegando ao pós-moderno. Ele retrata o movimento cultural de 60 como

[...]movimento cultural de efeito poderoso como o de um tufão que veio destelhando o que encontrava pela frente", que culminaram no emblemático ano de 68 , com um desejo de quebra de paradigmas estampado à flor da pele, injetado pelo rock'in roll, pela pílula anticoncepcional, pelos primeiros efeitos da revolução feminina, e pelo anúncio, no campo das ciências esotéricas, da chamada Era de Aquário, por Alice Blay, em 1972, para o início do III milênio (PEREIRA, 2005, p. 2)

O Pós-modernismo é o nome aplicado às mudanças ocorridas nas ciências, nas artes e nas sociedades avançadas, desde 1950.

Ele nasce com a arquitetura e a computação nos anos 50. Toma corpo com a arte Pop nos anos 60. Cresce ao entrar pela filosofia, durante os anos 70, como crítica da cultura ocidental. E amadure hoje, alastrando-se na moda, no cinema, na música e no cotidiano programado pela tecnociência (ciência + tecnologia invadindo o cotidiano com desde alimentos processados até microcomputadores), sem que ninguém saiba se é decadência ou renascimento cultural. (SANTOS, 2004, p. 8).

Após a $2^{a}$ Guerra Mundial, inicia-se a incredulidade perante o metadiscurso filosóficometafísico com suas pretensões atemporais e universalizantes. Sendo assim, a contemporaneidade é anti-totalitária, isto é, democraticamente fragmentada, e serve para afiar a nossa inteligência para o que é heterogêneo, marginal, marginalizado, cotidiano, a fim de que a razão histórica ali enxergue novos objetos de estudo. Perde-se a grandiosidade, ganha-se a tolerância. (LYOTARD, 2002). Como conseqüência dessa inclusão das diversas narrativas e verdades, uma característica que se evidencia no mundo contemporâneo é a fragmentação e, junto à ela, a aceitação/inclusão das diferenças, assim como a construção e permanente reconstrução de novas identidades. Diríamos que o mundo contemporâneo constitui-se num tempo marcado pela multiplicidade difusa que Ihe caracteriza. O momento atual reconhece a fragmentação, a efemeridade, a ambigüidade, as contradições, as descontinuidades, as múltiplas verdades.

A partir disso, alguns traços marcantes adquirem notoriedade na sociedade atual, tais como:

inclusão da corporeidade; anúncio da visão holística da sociedade do futuro e da produção do conhecimento - novo paradigma de ciência aí inscrito em profundo diálogo, por exemplo, com as religiões; implosão das metanarrativas grandiloqüentes da modernidade e seus conceitos básicos: Estado, classe social, trabalho, masculinidade, sexualidade, etc.; crise da instituições de 
sustento do paradigma anterior: família, moral, etc.; quebra dos valores "eternos" da civilização em declínio; deserção dos valores da "alta cultura" iluminista, cedendo a outras formas de manifestação cultural antes soterradas - a cultura afro, por exemplo; quebra da lógica da atuação revolucionária do antigo sujeito de classes (revolução molar) em prol de outro paradigma revolucionário (revolução molecular) no campo do desejo; aparecimento de novas linguagens em todos os âmbitos de ação e das relações humanas; inclusão das diferenças, antes negadas ou ocultas, no movimento das chamadas minorias como espaços do novo sujeito coletivo e suas formas moleculares de revolução; inclusão do conhecimento em rede - computador, Internet, etc. como fator irreversível; inclusão do mercado como vetor das relações sociais, e outros traços (PEREIRA, 2005, p. 6)

Para melhor ilustrar esta contemporaneidade na qual estamos inseridos, que se apresenta tão múltipla, fugaz, efêmera, composta de diversos paradoxos, Pereira expõe outros traços marcantes que nos interessa serem aqui apresentados, mesmo que de maneira sucinta, a fim de enunciar que essas idéias, presentes no contexto contemporâneo, muitas vezes, aparecem também nas obras de arte como forma de discussão de temas e questões, ou mesmo em sua composição. Esses traços são:

A crise da razão; [...] a impossibilidade (provisória) de engendrar valores duradouros; heteronomia ao mercado como necessidade, mas também como "miragem e ilusão" - o mercado "senhor de tudo"; submissão aos ditames da publicidade e emergência da cultura de massas impondo uma homogeneidade, ou "pasteurização" da cultura como mero entretenimento - o lugar ocupado pelas programações de TV, por exemplo; dissolução do sentido de História que se reflete numa visível "desmemorialização" principalmente das gerações mais jovens; crise mundial da educação em processo de profunda mudança mas em estado de "descrença geral" sobre seus reais efeitos; crise da fé no progresso ilimitado [...]; fim da crença nas cosmovisões devido à crise das metanarrativas; implosão do sujeito moderno o da revolução molecular; narcisismo e hedonismo exacerbados; corpolatria - por exemplo, na febre de "malhações" em academias; necessidade de viver o belo (nova estética); atendimento às necessidades de cada um como expressão do individualismo e do relativismo ético: minha liberdade termina onde começa a sua e vice-versa, como se ouve, alhures; emergência da "psi" como sucedâneo da fé necessidade de absorção de uma literatura de auto-ajuda - expressão do sentimento de abandono do sujeito, antes senhor de suas ações de mudança (PEREIRA, 2005, p. 6).

O contexto atual caracteriza-se como um contexto complexo, múltiplo, indefinido, que toma rumos diversos, assim como o homem e mulher do nosso tempo, em crise, em transformação, em busca da auto-afirmação e da prometida felicidade que o progresso não garantiu a todos. 
Segundo Harvey (1992), é um contexto bastante complexo que a contemporaneidade comporta no campo artístico, ora a arte sendo efêmera e fugidia, ora sendo eterna e imutável. É um campo minado e, muitas vezes, extremamente fértil de mudanças, crises e rupturas. Neste campo encontram-se os objetos, os happenings ${ }^{4}$, as performances ${ }^{5}$, a vídeo-arte $^{6}$, a land $a r t^{7}$, a arte do computador $^{8}$, a instalação ${ }^{9}$ e também o cinema, a propaganda, as telenovelas, entre tantas outras. As imagens "invadem" o mundo atual de forma acentuada e crescente.

E, neste contexto "encharcado" de imagens, de experiências estéticas, de manifestações artísticas, é concebível que muitos não entendam a arte contemporânea, caindo na inevitável pergunta: isso é arte? Talvez o seu não compromisso com a lógica, com algo que deva ser comprovado, é que a torna incompreensível. Talvez a sua complexidade, faça parte da própria complexidade humana.

Com o questionamento às metanarrativas, por exemplo, algumas características da arte que vinham-se apresentando até então são postas em questão. Não há um estilo único a ser seguido e a arte rompe fronteiras no que se refere às linguagens e aos materiais usados. A "verdade" não mais é única.

O questionamento às grandes metanarrativas significa a decadência ou, ao menos, não mais a supremacia das grandes idéias, valores e instituições ocidentais como Deus, verdade, família, cristianismo, conhecimento científico, etc. - os discursos globais e totalizantes. Busca-se, junto a estes, também o "desenvolvimento e valorização de temas antes considerados menores ou marginais em filosofia: desejo, loucura, sexualidade, linguagem, poesia, sociedades primitivas, jogo, o cotidiano" (SANTOS, 2004 , p. 73 - 74).

O cotidiano na arte contemporânea não aparece somente nos materiais e suportes usados como também nos temas, nas questões que os artistas propõem através de suas obras. Há, por exemplo, muitos artistas que falam de si, artistas fazendo histórias de

\footnotetext{
${ }^{4}$ happenings: significa acontecimento. Os artistas não produzem um produto final sendo o acontecimento o próprio produto. Normalmente o próprio artista é quem realiza o acontecimento, utilizando-se do próprio corpo. ${ }_{5}$ performances: trabalho artístico apresentado ao público sob a forma de uma ação (teatral). As primeiras performances foram apresentadas durante os anos 60 no quadro de movimento Fluxus, que visava ao alargamento do conceito de arte.

${ }^{6}$ vídeo-arte: campo da produção artística contemporânea que abrange os trabalhos em que o vídeo é usado como suporte e que explora seus recursos de linguagem.

7 land art: os trabalhos são realizados fora do ateliê, em desertos, lagos secos ou florestas, destinado a durar pouco, com ausência do espectador. As obras chegam ao museu ou galerias na forma de fotos, mapas, vídeos ou filmes.

${ }^{8}$ Arte do computador: arte que utiliza os meios oferecidos pelas novas mídias, como a informática e a Internet.

${ }^{9}$ Instalação: obra de arte que integra o espaço de exposição como um componente estético. Constituem-se em obras tridimensionais, criadas com diversos materiais e objetos, incluindo luzes de neon e cuja colocação é variável conforme o local. É criada na relação com o espaço. O artista entende o lugar e cria a partir dele. Também permite um conjunto de linguagens.
} 
vida, auto-referência, imbuídas de tonalidades pessoais e íntimas. Um exemplo a que podemos nos referir é a artista Keila Alaver, que sempre trabalhou com o tema autoretrato.

Sua maneira de lidar com ele estabelece um comentário ao mesmo tempo absurdo e irremediavelmente sensato, a respeito do estranhamento e da sensação de solidão, de artificialismo e de distanciamento que a sociedade contemporânea impinge a cada pessoa (CANTON, 2001, p. 69).

A obra "Karen, Sandra, Ellen, Eliane, Henry, Keila e Chico", de 1996, trata de uma caixa de luz (backlights), com imagens trabalhadas no computador em que sua fotografia se justapõe à imagem de outras crianças, todas transformadas em bonecos autômatos, com expressões vazias, congeladas, realizando atos cotidianos.

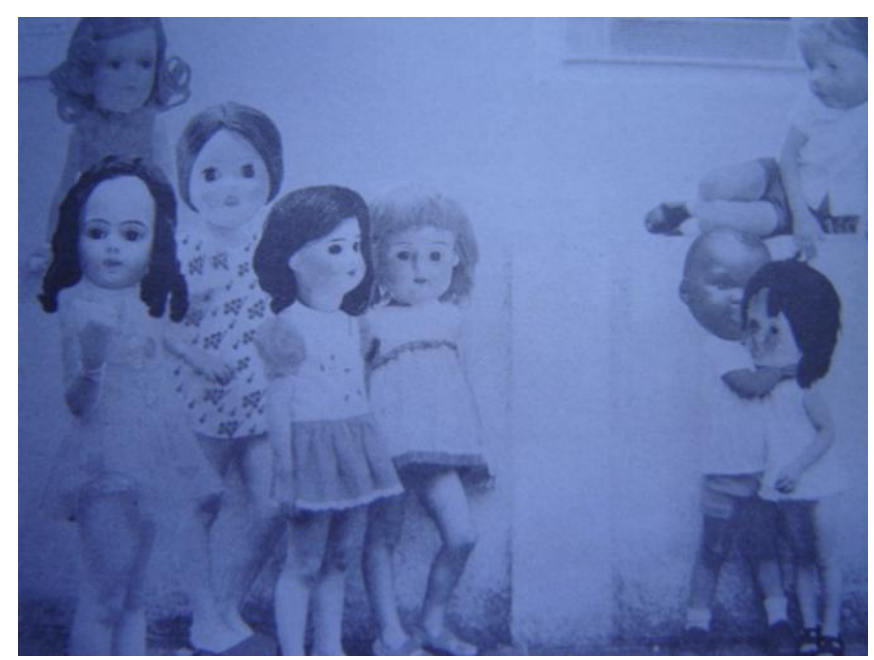

Figura.01 Karen, Sandra, Ellen, Eliane, Henry, Keila e Chico - Keila Alaver

O cotidiano aparece também na discussão de temas como sexualidade, gênero, trabalho, temas sociais, identidade e anonimato, entre tantos outros. Como exemplo, podemos citar o artista Hélio Melo, que em

[...]suas séries intermináveis somam sapatos, recolhidos nas ruas, lixos e brechós da cidade. São sapatos únicos, sem pares, que o artista enfileira e compõe com outros, formando uma tapeçaria estranha, cheia de história e, ao mesmo tempo, anonimato. Nesse colecionismo, o artista busca também apontar a sociedade e o contexto de contraste entre riqueza e pobreza, estendendo ao trabalho aspectos políticos. Seu trabalho recente inclui autoimagens fotográficas inseridas em cenas inusitadas. (CANTON, 2001, p. 65-66). 


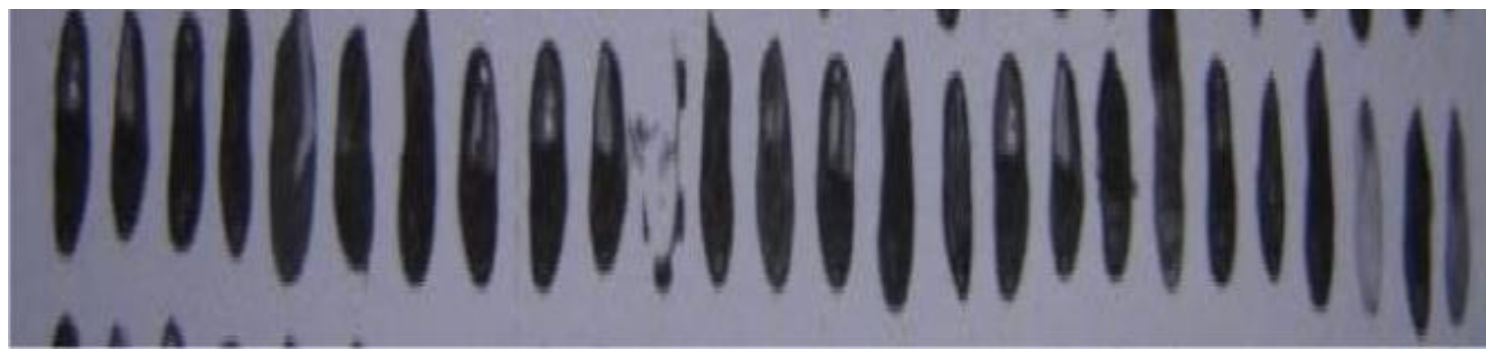

Figura.02 Sem Título - Hélio Melo

Se Deus e a igreja já haviam sidos questionados anteriormente, já no início da Modernidade, o questionamento à ciência é bem mais recente, uma vez que a própria Modernidade foi quem a fortaleceu como única verdade, deixando de lado outras dimensões também necessárias ao ser humano. Sendo assim, no momento em que se questiona as grandes verdades, outras dimensões da vida, para além do conhecimento científico, gradualmente vão sendo aceitos e/ou retomados como importantes. Constituiuse, então, um momento em que as verdades são tidas como provisórias. A ciência é uma entre outras verdades. Convivemos, como nunca antes, com as múltiplas formas de entendimento sobre as coisas, "o saber pós-moderno não é somente o instrumento dos poderes. Ele aguça nossa sensibilidade para as diferenças e reforça nossa capacidade de suportar o incomensurável." (LYOTARD, 2002, p. 17).

A cultura é uma dessas outras dimensões que passa a ser olhada como importante e significativa na constituição dos sujeitos e das sociedades, na constituição do mundo contemporâneo. Por muito tempo, ela foi olhada enquanto uma dimensão inferior às outras. Tínhamos um olhar naturalista sobre muitas coisas e a criação divina e biológica foi destinada a definir e responder a muitas questões que hoje passam a serem explicadas também pela cultura em que estamos inseridos.

Os movimentos da década de 60 foram movimentos de intensa modificação e influência acerca do pensamento moderno em relação à cultura. Eles deram maior significação a essa dimensão e trouxeram um novo e intenso olhar a ela. Todos estes movimentos, de formas diversas, questionaram o posto, o dado, o natural, o estabelecido. Hall (2003, p. 44) aponta o feminismo como o exemplo principal desses movimentos. Junto ao feminismo, acrescentam-se os movimentos estudantis (como o famoso 1968) e os de contra-cultura, bem como os movimentos revolucionários de então. Com sua mobilização mostraram que o que era "natural", como a diferença homem-mulher, ou o que era (e é, para muitos ainda) "anormal", como o homossexualismo, não passava de construções sociais. 
Assim, a cultura na qual o artista está mergulhado influencia no seu pensamento e na construção de sua obra e, por conseqüência na compreensão do espectador. $O$ artista reflete questões do seu tempo e dos pensamentos dos homens e mulheres deste tempo. Ser artista não é dom divino ou natural, é construção. O artista não é diferente dos outros, vive e trabalha diariamente como todos os outros profissionais. Neste contexto, ele é visto enquanto um profissional, não mais o gênio criador, nem mais um exímio artífice de sua técnica.

Sendo a criação uma construção do artista, que toma "emprestado" aquilo que está ao seu redor para criar sua arte, incluindo o que a história deixou, o novo na arte não mais significa algo puramente criado, distante do cotidiano. $O$ artista apropria-se de elementos materiais e outras imagens já existentes, frutos tanto da indústria cultural, como do mercado e dos elementos da cultura popular. Com isso, também aproximam-se arte erudita e arte popular.

Uma das conseqüências de a arte ter-se livrado do desenvolvimento passo a passo era a liberdade de buscar inspiração em toda parte: [...] ela agora não precisava restringirse às belas-artes ou às artes "elevadas", mas também podia empregar o artesanato ou outras técnicas, materiais e temas culturais "inferiores" onde the parecesse adequado (ARCHER, 2001, p. 155-156).

Hoje o artista não quer romper com o passado, como foi no Modernismo. Traz à sua arte a citação, a apropriação, a colagem, valoriza os modelos de referência, "recombina" o que já existe e o apresenta de outra maneira. "A citação podia aparecer sob inúmeras formas - cópia, pastiche, referência irônica, imitação, duplicação, e assim por diante -, mas por mais que seu efeito fosse surpreendente, ela não poderia reivindicar a originalidade" (ARCHER, 2001, p. 156). Há um reencontro com a tradição, buscando referências no passado, diferente do Modernismo, que ditava o novo e o rompimento com a tradição.

Disso conclui-se também que, para ser contemporâneo, o artista não necessita expressar-se somente a partir das linguagens recentes e nem somente pelas tecnologias mais atuais, "nem todo artista precisa trabalhar com instalação, vídeo, performance ou intervenção para ser contemporâneo. Há aqueles que seguem fiéis às mídias tradicionais - pintura, escultura, gravura ou desenho - e nem por isso são menos atuais" (ALBUQUERQUE, 2005g, p. 40).

Um exemplo de artista que é contemporâneo na pintura é o artista Franz Ackermann. Ele é a prova de que a pintura não morreu e de que, para ser contemporâneo não necessariamente era preciso estar no campo da fotografia, ou do cinema, da arte conceitual, da instalação ou outra linguagem das mais recentes. 
Nos seus quadros de grande formato, que ocupam por vezes a totalidade do espaço, ele trabalha de maneira sugestiva com a nossa percepção do mundo exterior, as suas estruturas, as suas cores, as suas formas, as suas ilusões, os seus clichês cheios de associações (RIEMSCHNEIDER/GROSENICK, s/d, p. 10).

Ackermann já trabalhou com pequenas aquarelas em formato "de bolso", os "Mental Maps". Mas a partir de 1997, o artista trabalha cada vez mais com o conceito de pintura total.

Algumas pinturas são comprimidas pelas linhas das paredes ou são aplicadas directamente nas paredes, integradas num panorama espacial que provoca o efeito de um círculo cinematográfico sem fim. No projecto <<Songline>>, 1998, Ackermann criou um módulo espacial transportável que rodeava e fechava totalmente o espectador. A este trabalho acrescentam-se igualmente fotografias publicitárias, e espelhos que reflectem as sugestões mediáticas da experiência do mundo e da sua problemática (RIEMSCHNEIDER/GROSENICK, s/d, p. 10-11).

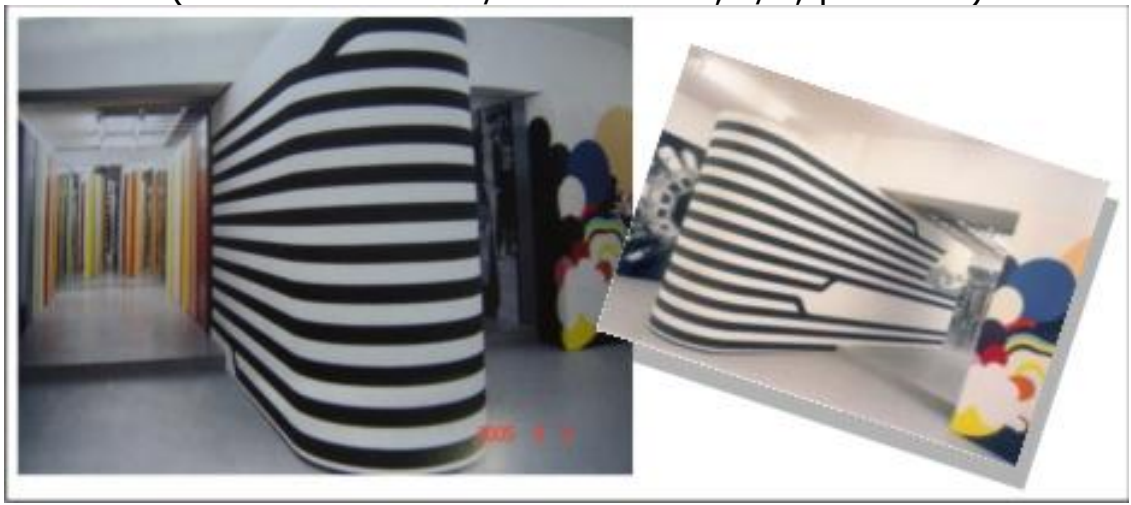

Figura.03 Songline - Franz Ackermann

Outro exemplo de contemporâneo na pintura é a artista Karin Lambrecht. Suas obras tratam de pinturas atípicas que lidam com terra, sangue de animais, tecidos queimados e/ou rasgados. Assim,

As cores de suas telas são extraídas não de tubos de tintas industrializadas, mas de pigmentos naturais, indo desde os grãos de terra até o sangue derramado no abate de animais. Muitas vezes, essas obras são realizadas ao ar livre, com a artista tomando uma vassoura como pincel, para depois deixá-las ao relento, sujeitas à ação do sol, do vento e da chuva, que lhes vão alterando ainda mais a aparência, como se fossem co-autores autônomos da obra, que não compartilham com a artista o rumo que está sendo dado, como o tecido e a estrutura de madeira, as cores que vão sobre as telas pertencem ao mundo; não são elementos idealizados; trazem dele o peso, a textura, o cheiro. (FARIAS, 2002, p. 56). 


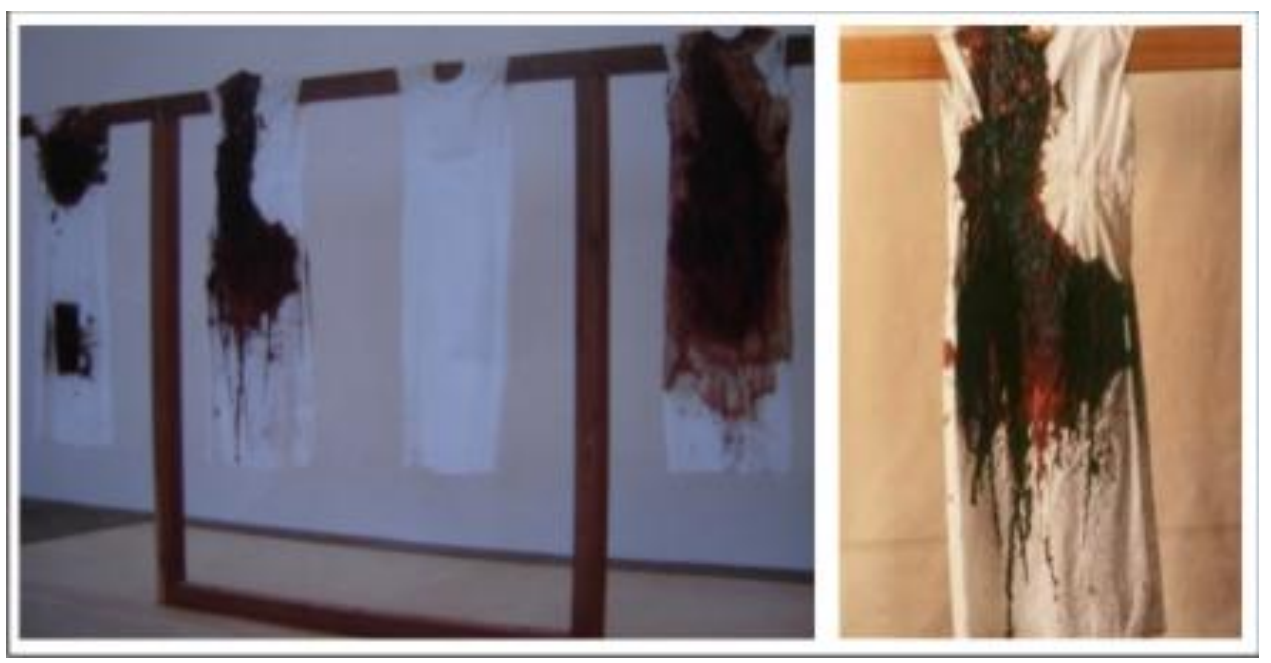

Figura.04 Sem Título - Karin Lambrecht

No contemporâneo, a idéia de autoria, tão marcada e valorizada durante todo o período da Arte Moderna, começa a se dissipar no momento em que artistas propõem as suas criações em conjunto com outros profissionais. "Até hoje, grande parte dos trabalhos que se utilizam de tecnologias de ponta necessitam de parcerias com engenheiros, biólogos e programadores para serem viabilizados" (ALBUQUERQUE, 2005f, p. 34).

Também nessa idéia de dissipação da autoria, discute-se a participação do público. Muitas obras que pedem a interação das pessoas, na Internet, por exemplo, muitas vezes não sabe o seu produto final, no que vai resultar. É também a valorização do processo.

Ao se observar uma pintura de Rembrandt ou Monet, também não é possível enxergar todo o processo criativo que está por trás dela. A diferença é que, para esses pintores, suas telas funcionavam como síntese daquilo que buscavam exprimir, enquanto, para muitos artistas contemporâneos, o que resta de seus trabalhos nem sempre tem o mesmo valor da experiência ou da idéia que os produziu (ALBUQUERQUE, 2005, p. 27).

O artista de hoje não mais se identifica com um estilo único ou participa de movimentos, até porque eles quase não existem mais. Sua identidade também não é mais única.

A arte contemporânea é avessa à idéia de uniformidade. Mas essa não é uma particularidade da produção artística. A multiplicidade é marca dos tempos atuais, seja na ciência, na filosofia, na gastronomia, na televisão. É o famoso 'de tudo um pouco', que caracteriza quase todos os campos da cultura e permite que artistas e pensadores dêem vazão a múltiplas experiências, propostas e reflexões (ALBUQUERQUE, 2005b, p. 12).

A noção de identidade está diretamente ligada à idéia de sujeito. Da idéia de um sujeito moderno centrado, "dotado das capacidades de razão, de consciência e de ação" (HALL, 
2003, p. 10), o qual é buscado pela Modernidade, passamos a um sujeito sendo formado pelo seu entorno, em interação social, nem sempre pertencente a uma única identidade. "O sujeito, previamente vivido como tendo uma identidade unificada e estável, está tornando-se fragmentado; composto não de uma única, mas de várias identidades, algumas vezes contraditórias ou não resolvidas" (HALL, 2003, p. 12).

O entendimento que tínhamos de uma identidade única, desde os nascimentos até a morte, coloca uma idéia naturalista sobre nossa formação identitária e de sujeito.

A identidade plenamente unificada, completa, segura e coerente é uma fantasia. Ao invés disso, à medida em que os sistemas de significação e representação cultural se multiplicam, somos confrontados por uma multiplicidade desconcertante e cambiante de identidades possíveis, com cada uma das quais poderíamos nos identificar - ao menos temporariamente (HALL, 2003, p.13).

A globalização foi fator fundamental que também fragmentou o sujeito e sua identidade, tanto cultural quanto individual, assim como as tornou provisórias, de mudança constante e rápida. "As sociedades da modernidade tardia são caracterizadas pela diferença; elas são atravessadas por diferentes divisões e antagonismos sociais que produzem uma variedade de diferentes posições do sujeito - isto é, identidades" (HALL, 2003, p. 17).

Segundo SILVA,

vivemos num mundo social no qual novas identidades culturais e sociais emergem, se afirmam, apagando fronteiras, transgredindo proibições e tabus identitários, num tempo de deliciosos cruzamentos de fronteiras, de um fascinante processo de hibridização de identidades. É um privilégio, uma dádiva, uma alegria viver num tempo como esse, num tempo assim. (2003, p. 7).

Mas, ainda segundo ele, também estamos vivendo num mundo em que muitas pessoas sofrem exclusões, um número altíssimo de pessoas estão excluídas de um projeto de uma vida vivida com qualidade.

A diversidade/pluralidade entra com força enquanto uma das características mais marcantes também da arte contemporânea, tanto no que se refere à escolha de materiais e suportes, quanto nas linguagens artísticas.

Ao lado de vídeos e instalações, convivem democraticamente fotografias, objetos, performances, intervenções e até mesmo pinturas. E não se está falando em uma diversidade de categorias. Até porque hoje em dia é complicado delimitá-las. (ALBUQUERQUE, 2005b, p. 12). 
Aí caracteriza-se outro item importante na arte de hoje: as fronteiras entre as linguagens quase não existem ou são muito tênues, assim como misturam-se várias, dependendo da proposta do artista. "O que os artistas propõem é justamente esta falta de limites. Não há mais clareza quanto às fronteiras do campo artístico. Tudo é possível" (ALBUQUERQUE, 2005 , p. 12). Não sendo a arte eclética só nas categorias, as linguagens de hoje se misturam, dificultando a possibilidade de nominá-las.

Antes, cada linguagem estava voltada para si mesma: a pintura discutia elementos estritamente pictóricos, a escultura questionava elementos estritamente escultóricos e assim por diante. [...] Com a crise da arte moderna, a gente passa a ter expressões que não são nem escultura, nem pintura, nem desenho, mas carregam vários desses elementos (FARIAS, 2005, p. 14).

Até o início do século $X X$, os artistas, não arriscavam muito quanto à escolha dos materiais usados e nem na mistura deles. Nas artes visuais a pintura era pintura, não se agregava a ela outros recursos como colagem, por exemplo. Os artistas mantinham a tradição de usar tintas para a pintura; gesso, argila, bronze (em separado) para esculturas. Os movimentos das vanguardas históricas (Cubismo, Dadaísmo, Surrealismo, etc.), mostraram toda a sua força como movimentos que iniciaram o processo de ruptura formal dos limites na arte.

A artista Nora Correas ao criar a instalação Instalación América para a Cidade dos Contêineres na III Bienal do Mercosul, em 2001, apresenta um exemplo de que as linguagens não têm fronteiras delimitadas. Nela, a artista apresentou suas idéias de questionamento à violência através do recurso do objeto: vários revólveres de brinquedo instalados nas duas laterais do contêiner. Na mesma instalação, à frente, uma produção em vídeo mostrava cenas fragmentadas e repetidas de violência. Ao entrar no contêiner o público também ouvia sons de tiros, gritos, horrores da violência, intercalados de um silêncio agoniante, quase mortal.

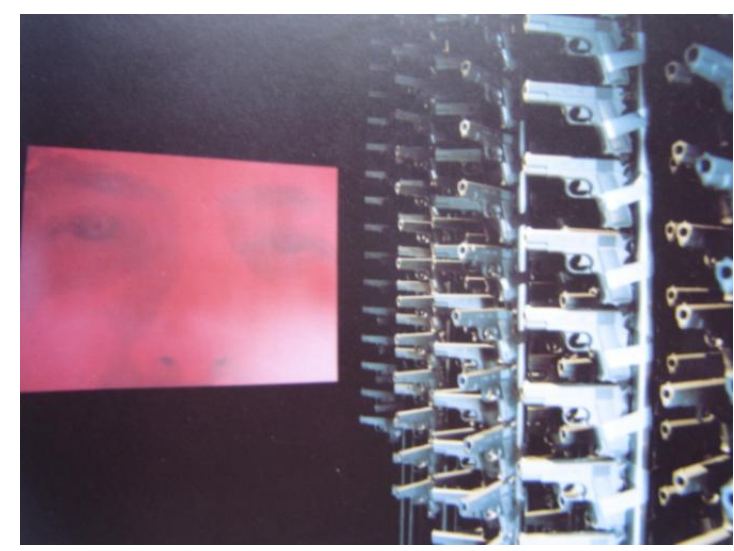

Figura.05 Instalación América - Nora Correas 
A aceitação às diferenças e à diversidade também levou a arte à propostas diferentes no que se refere ao espaço da obra. Hoje, as obras não são mais somente aquelas que encontramos nos espaços de museus e galerias. Ampliam-se as possibilidades em que se realiza a obra: espaço urbano, parques, desertos, rios.

A idéia de aproximar a arte da vida inspirou um número expressivo de artistas a levar o seu trabalho para as ruas, principalmente a partir dos anos 60, a pretensa neutralidade dos espaços expositivos tradicionais - o chamado "cubo branco" do museu e da galeria - foi deixada de lado em prol da profusão de elementos e interferências que a cidade proporcionava. A proposta consistia em produzir trabalhos que se relacionassem intimamente com 0 contexto onde eram criados. Nem todos, entretanto, voltaram-se para a urbe. Houve quem buscasse locais mais afastados, como desertos e praias, produzindo trabalhos que muitas vezes só podiam ser observados por meio de filmes e fotografias (ALBUQUERQUE, 2005e, p. 44).

A arte em lugares públicos é criada a partir de sua plena relação com o ambiente, de onde retira sua razão de ser. Ela dialoga com o espaço, anterior à sua realização, durante e também com o espectador que a vivencia.

Esta forma de trabalho exige uma pesquisa prévia do lugar a que se destina, a fim de conhecê-lo em profundidade, em vários níveis de informação e como deveria ser a resposta escultural "a habilidade estética, nível e espécie de fisicalidade, gestualidade, utilidade ou inutilidade, se escultural ou arquitetural, ou ainda simplesmente plantando uma árvore ou nada fazendo". (BARROS, 1999, p. 89).

A intervenção urbana tem sido uma linguagem bastante explorada pelos artistas contemporâneos. Os espaços públicos das cidades tornam-se locais de troca, convivência e experiência entre o artista, sua obra e o público passante.

Christo, artista que explora uma nova perspectiva artística, propõe ações de "empacotamento" em prédios, pontes, monumentos, parques, etc., interferindo no olhar cotidiano das pessoas sobre estes locais, recriando "um estado de curiosidade em relação a fatores ambientais que haviam se tornado costumeiros e, portanto, desinteressantes." (ARGAN, 1992, p. 589). 


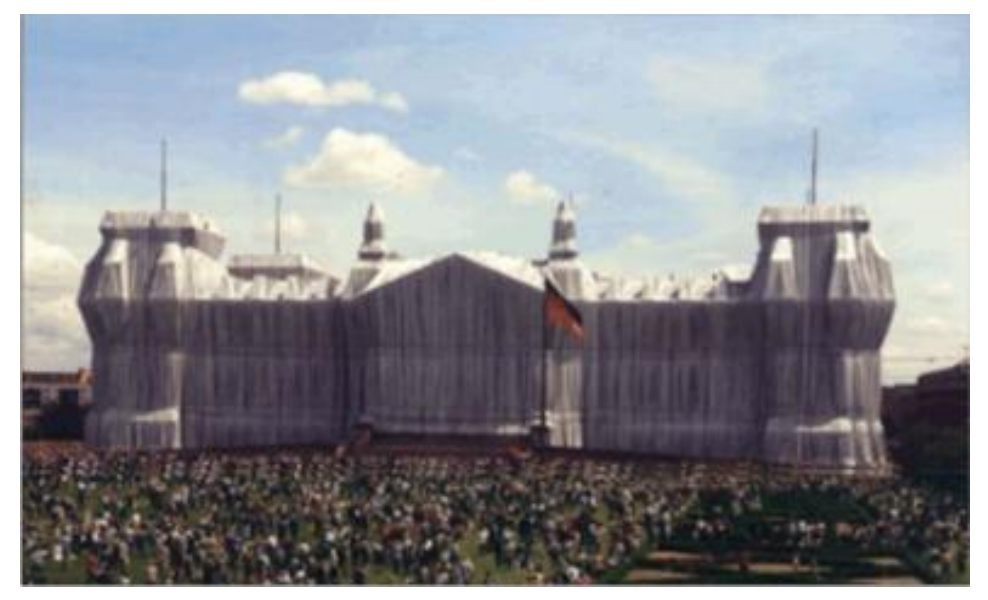

Figura.06 The Reichstag -Christo

Além de os artistas levarem a sua arte para a rua e outros ambientes, reconfigurando o espaço e o suporte das obras, também as artes de agora se propõem a adotar e a acolher, de maneira afirmativa a fragmentação e a efemeridade.

O primeiro aspecto percebido em que a fragmentação está presente na arte é o fato de cada artista criar seu próprio universo. Por isso, "é impossível falar em tendências ou movimentos na arte de hoje. Muito menos em uniformidade. A fragmentação é um dado do nosso tempo. Daí a imagem do arquipélago. No início do século, você até identificava vertentes, mas hoje é complicado fazer reduções". (FARIAS, 2005, p. 14).

Agnaldo Farias explicita a idéia de arquipélago dizendo que a arte contemporânea, embora possuindo suas matrizes em outros tempos históricos, "avança num número tal de direções e é construído por obras tão singulares que [...] sugere um arquipélago" (FARIAS, 2002, p. 19). A idéia de arquipélago é também porque as manifestações artísticas atuais fogem das grandes reduções e valorizam as diferenças. "Um arquipélago porque cada boa obra engendra uma ilha, com topografia, atmosfera e vegetação particulares, eventualmente semelhante a outra ilha, mas sem confundir-se com ela. Percorrê-la com cuidado equivale a vivenciá-la, perceber o que só ela oferece" (FARIAS, 2002, p. 20).

Mas a fragmentação não aparece na arte somente desta forma. As próprias criações artísticas não são totalmente narrativas: os elementos visuais e o tema aparecem muitas vezes em ritmos descontínuos, fragmentados (mas nem por isso deixam de apresentar uma totalidade), o que exige uma leitura e uma sensibilidade mais apurada para sua compreensão.

A efemeridade, talvez a característica mais desconcertante na arte visual contemporânea é uma característica fortemente presente no mundo atual, nos mais diferentes âmbitos - 
no cotidiano, nas relações, nos valores, na medicina, no trabalho, no mercado. A efemeridade na arte apresenta-se tanto na escolha de materiais quanto nas linguagens que o artista escolhe: a performance, o happening, as instalações, são linguagens da arte contemporâneas que expressam algo do momento. O registro fica através de vídeos, fotos, documentos e, às vezes, não há registro algum. Muitas instalações são reinventadas a cada nova exposição, pois o espaço é outro.

Os materiais inusitados são constantemente recorridos nas criações contemporâneas. Vik Muniz, por exemplo, consagrou-se fazendo suas criações com comida. É o caso de uma de suas obras "Séries Imagens de Chocolate", em que o artista retrata várias pessoas "desenhadas" com chocolate. E depois fotografa. Aqui o artista nos coloca outra questão: "estamos diante do registro de uma obra? Ou o registro é a obra em si?" (FARIAS, 2002, p. 75).

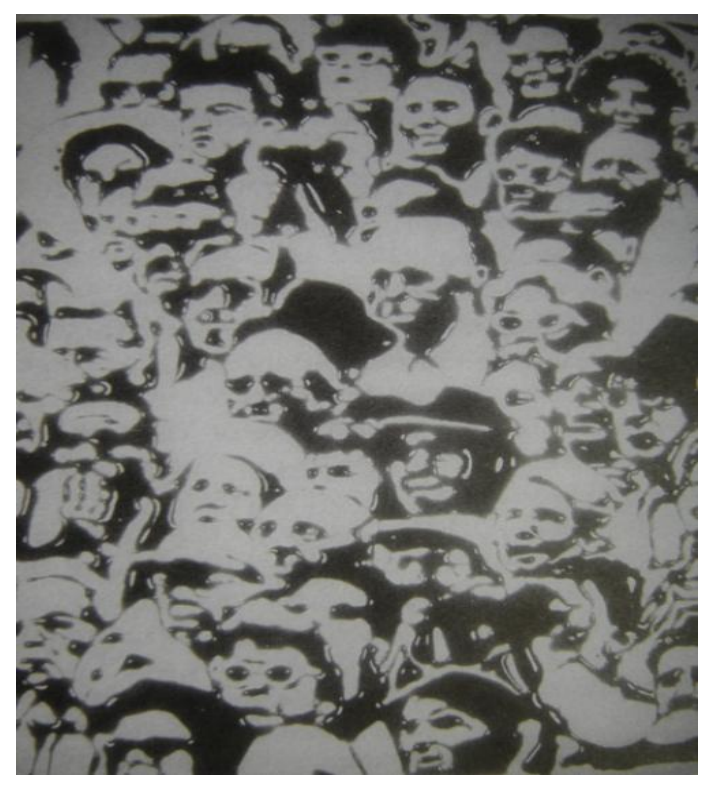

Figura.07 Séries Imagens de Chocolate - Vik Muniz

Os artistas, desde os primórdios, utilizam-se para criar dos mais diversos recursos, tanto tecnológicos quanto outros, gerados pelos processos da globalização e pelo crescimento e descobertas científicas e tecnológicas. Pela globalização recente a arte contemporânea é interferida pela troca/interferência de conceitos, culturas, signos, símbolos. Ampliam-se e multiplicam-se as possibilidades de aproximação das diferentes culturas. Nunca antes foi possível uma proximidade entre culturas num espaço de tempo tão curto e tão rápido. Isso não significa dizer que não temos mais centros hegemônicos. Ao contrário, a globalização crescente foi gerando uma maior centralidade.

O que acontece, neste tempo atual é que novas tecnologias são criadas num espaço de tempo cada vez mais curto entre uma e outra e o artista está constantemente recorrendo 
a elas para expressar suas questões. "Após a revolução industrial, no século XVIII e a microeletrônica no século XX, essas relações se intensificam muito" (ALBUQUERQUE, 2005 , p. 34). E, quando as experiências com as tecnologias deste período já estavam sendo mais exploradas, surgem novas tecnologias e criações "a partir dos anos 60 com a invenção do computador e do videoteipe. Mais tarde, tecnologias como o fax e o xerox também foram incorporados pelos artistas" (ALBUQUERQUE, 2005f, p. 34-35), disseminando-se nas décadas seguintes com uma rapidez e aceitação bastante significativa no meio artístico.

Porém, as crescentes e intermináveis descobertas em diferentes campos não param por aí, e surgem cada vez mais rápido. "Dos anos 90 para cá, recursos como o desenvolvimento de softwares, a manipulação genética, a robótica, a telepresença e até mesmo a cirurgia plástica passam a ser empregadas em criações que desafiam os limites entre arte e ciência" (ALBUQUERQUE, 2005f, p. 35).

Conforme Domingues:

Hoje, tudo passa pelas tecnologias: a religião, a indústria, a ciência, a educação, entre outros campos da atividade humana, estão utilizando intensamente as redes de comunicação, a informação computadorizada; e a humanidade está marcada pelos desafios políticos, econômicos e sociais decorrentes das tecnologias. A arte tecnológica também assume essa relação direta com a vida, gerando produções que levam o homem a repensar sua própria condição humana (1997, p. 17).

As novas tecnologias tornam-se um meio de criação para a arte. Nela o artista precisa operar com os códigos próprios para que a obra seja significativa, sem perder de vista a poética, encontrando maneiras criativas de falar de aspectos e temas relevantes e contemporâneos. Os caminhos da experiência estética com as novas tecnologias se alteram, uma vez que modificados os meios para expressão, os dispositivos são outros, que acenam uma

[...]arte da participação, de interação, da comunicação planetária [...] Fala-se no fim da arte da representação em favor de uma arte interativa que é basicamente comportamental e que não pode se encerrar em objetos acabados como numa escultura, pintura, fotografia ou outro suporte material, nem mesmo no cinema ou no vídeo em seus formatos habituais que impedem o diálogo transformador (DOMINGUES, 1997, p. 17-18).

A exposição Ciberarte: zonas de interação, organizada para a II Bienal do Mercosul, em Porto Alegre, é toda marcada a partir de propostas interativas da arte e da tecnologia e desta arte com o espectador. No campo das ciberinstalações, por exemplo, 
[...]é oferecida a exploração física de ambientes de instalações interativas que contam com sistemas e interfaces para a aquisição e comunicação de dados em produções criativas com processamento de sinais: toque, sopro, calor ou outro tipo de sinal são traduzidos em paradigmas computacionais. A interação nos ambientes propicia diálogos dos sistemas naturais e sistemas artificiais através da linguagem numérica. O corpo em sua atividade performática desencadeia relações com uma "obra dispositivo" e entra numa exploração física e psíquica do ambiente. (DOMINGUES, 2000, p. 41).

Nesta exposição, a proposta de Edmond Couchot e Michel Bret consistia em soprar sobre uma imagem.

Na parte de baixo da tela, ligada a um computador, há uma flor de dente-de-leão. Quando se sopre a flor, por meio de um captor colocado em cima de uma placa transparente, solta-se uma grande quantidade de aquênios que voam com o vento. Cada flor se desmancha de certa maneira, rápida ou lentamente [...] (DOMINGUES, 2000, p. 44).

O que acontece é uma interação entre um objeto virtual dentro do computador e um elemento estranho, o sopro do espectador. "Não há pena, não há flor, não há movimento no espaço virtual do computador, e também não existem imagens sem esse sopro real, incitante. Cada experiência é única." (DOMINGUES, 2000, p. 44).

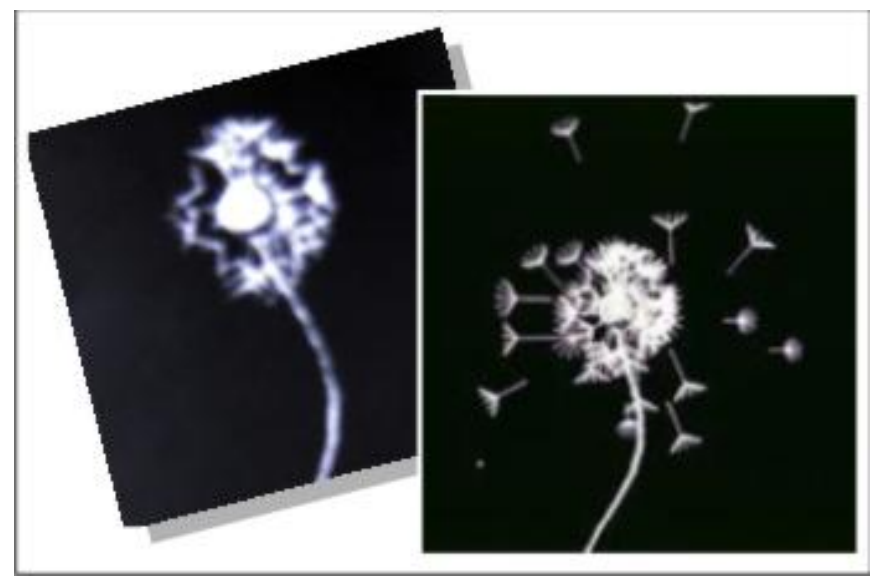

Figura.08 La plume et lê pissenlit - Edmond Couchot e Michel Bret

Já na década de 1920, aparecem as primeiras obras dadaístas, em que o público era instigado a agir de forma mais direta. Numa exposição o artista Max Ernest "exibiu uma de suas esculturas ao lado de um machado. A proposição era clara: caso não gostasse da obra, o visitante estava autorizado a destruí-la" (ALBUQUERQUE, 2005d, p. 19). 
A participação do espectador ou do público nas obras aconteceu de várias maneiras no decorrer da história. Ao contemplar a obra, o espectador já participa. Não se trata somente de uma interação direta, mas também conceitual.

Hélio Oiticica, por exemplo, propõe obras que giram em torno da participação do espectador, de formas variadas, seja pela contemplação, pela participação direta, seja pela participação emotiva ou experimental. Na participação experimental, Hélio Oiticica criou os parangolés que,

através do trabalho de descondicionamento do corpo, somado à exigência do artista de que as proposições sejam rigorosamente abertas, o indivíduo participa ativamente como criador. A obra só se concretiza através do outro: o participante. (JUSTINO, 1998, p. 122).

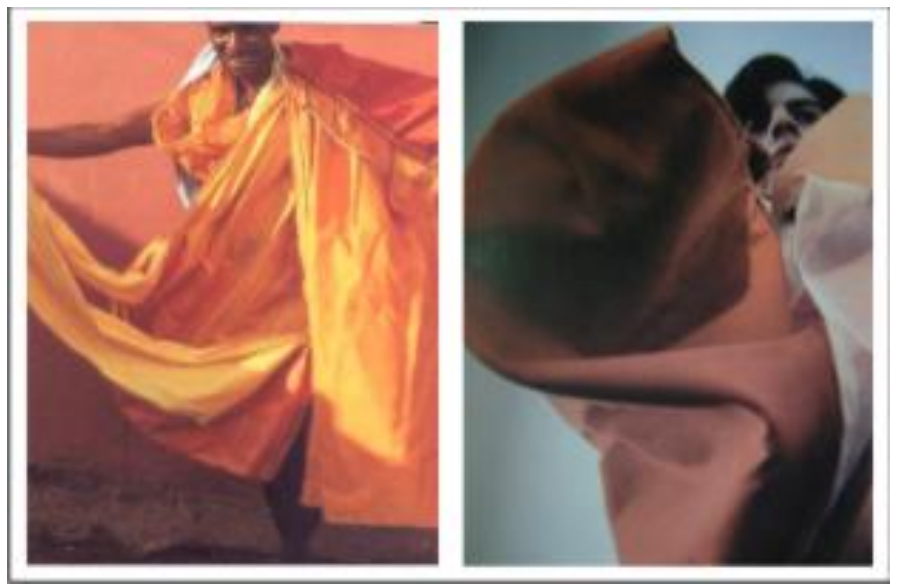

Figura.09 Romero veste Parangolé - Oiticica

Os recursos para a participação em Oiticica vão desde a manipulação da matéria e da experimentação da penetração em espaços, até a dança e as apropriações.

Este processo estimula corpo e cabeça, explorando a imaginação: o homem habita o imaginário. Sem renunciar a nenhuma fonte, a participação em Oiticica é dolorosamente lúcida. (JUSTINO, 1998, p. 123).

O corpo também se torna suporte da obra com muito mais freqüência que antes, sua participação não é mais só para contemplar ou interferir na obra, e sim, em algumas linguagens, ser o próprio suporte. Entram nesta categoria as performances, a body art ${ }^{10}$.

Para a compreensão da arte de hoje todos os sentidos são necessários. O corpo como um todo é chamado a envolver-se. Esta postura difere da arte anterior, uma vez que, no trajeto da modernidade, campos extremamente significativos e importantes para a

\footnotetext{
${ }^{10}$ body-art: arte que toma o corpo por tema e que faz dele o objeto central para a criação artística.
} 
condição humana foram sendo esquecidos e excluídos e o sensível foi deixado de lado por muito tempo.

Há também, junto a isso, uma característica da arte que a trata de forma intelectualizada, ao mesmo tempo em que continua a exigir um espectador sensível. Assim como tem envolvido mais o corpo, também exigem do espectador uma compreensão e um conhecimento mais ampliado do mundo, dotado de uma capacidade que, além de compreender fatos históricos e atuais e estar ao par dos acontecimentos e descobertas nos mais diferentes âmbitos, também seja capaz de estabelecer relações entre vivência/conhecimento/obra.

Uma obra que exemplifica essa relação de conhecimento histórico e social de hoje e de outrora é a obra "Missão/Missões (Como Construir Catedrais)" de 1987 feita por Cildo Meirelles. Esta obra, confeccionada com 600 mil moedas, 800 hóstias e 2 mil ossos é uma instalação de alto impacto dramático e retrata as "missões jesuíticas, no qual o alto custo de conversão dos índios combinou-se com uma violência que quase os exterminou" (FARIAS, 2002, p. 72). O nervo do projeto é feito de hóstias que liga o chão de ouro ao céu macabro, discutindo relações de poder da Igreja.

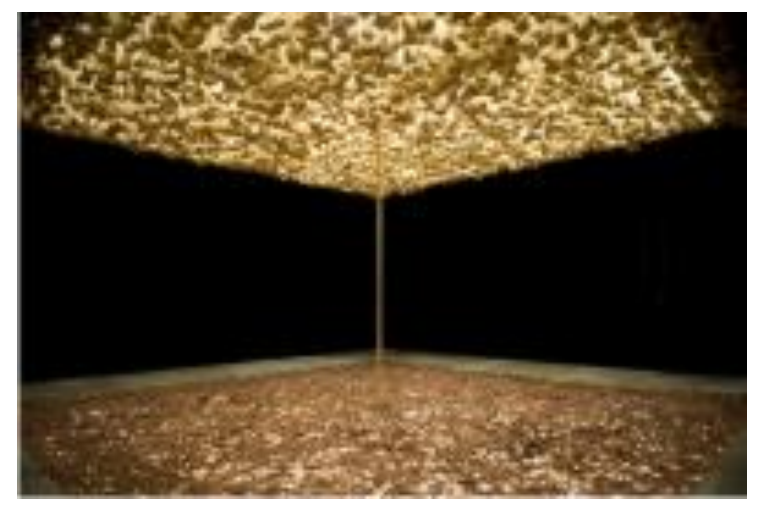

Figura.10 Missão/Missões (Como Construir Catedrais) - Cildo Meirelles

Estabelecendo os sentidos gerados entre a arte visual e o mundo contemporâneo, com suas múltiplas características, é possível compreender que as criações artísticas e os mais diferentes objetos e elementos da cultura visual são, portanto, meios de refletir e compreender as formas de pensamento da cultura da qual os produzem. Por esta razão, olhar para uma manifestação artística implica uma penetração mais profunda do que a meramente visual, significa um olhar na sociedade e na vida da sociedade, olhar situado e atento às nuances, cores, pensamentos, ações e diversidades que nela estão contidas. 
A escola tem sido um dos lugares possíveis de efervescência e discussão de tais questões, especialmente no que diz respeito ao ensino da arte. As grandes questões e características do mundo contemporâneo, que afetam diretamente o artista e a arte, também afetam a escola, os educandos e o ensino que nela se pretende efetivar.

É importante que, tanto os professores quanto os estudantes busquem entender o contexto em que a arte foi criada, o que permite perceber a ligação da arte com a vida e atribuir-lhe maior significado, estabelecendo diálogos que se fazem importantes e constitutivos de sentidos. Essas compreensões são necessárias para que seja possível a efetivação da aprendizagem das artes visuais contemporâneas nas escolas, mediada pelos professores, para que estes sejam capazes de proporcionar situações de aprendizagens que ampliem o repertório das crianças e jovens no que se refere ao mundo contemporâneo e que possam vivenciar de maneira mais efetiva a arte de seu tempo, compreendendo melhor o mundo em que vivem.

\section{Referências}

ALBUQUeRQUE, Fernanda. Mas isso é Arte? In: Revista Aplauso. Porto Alegre: v. 57, ano 7, p. 14-15, 2005a.

. De tudo um pouco. In: Revista Aplauso. Porto Alegre: v. 58, ano 7, p. 12, 2005b.

. O que vale é a idéia. In: Revista Aplauso. Porto Alegre: v. 59, ano 7, p. 27, 2005c.

. O público faz a obra. In: Revista Aplauso. Porto Alegre: v. 60, ano 7, p. 19, 2005d.

A arte invade a cidade. In: Revista Aplauso. Porto Alegre: v. 61, ano 7, p. 44, 2005 e.

. Arte, ciência e tecnologia. In: Revista Aplauso. Porto Alegre: v. 62, ano 7, p. 34-35, $2005 f$.

. Tradição renovada. In: Revista Aplauso. Porto Alegre: v. 63, ano 7, p. 40, 2005g.

ARCHER, Michael. Arte Contemporânea: Uma História Concisa. São Paulo: Martins Fontes, 2001.

ARGAN, Giulio Carlo. Arte Moderna. São Paulo: Companhia das Letras, 1992.

BARRoS, Anna. A Arte da Percepção: Um Namoro Entre a Luz e o Espaço. São Paulo:

Annablume, 1999. 
BERMAN, Marshall. Tudo que é sólido desmancha no ar: a aventura da modernidade.

São Paulo: Companhia das Letras, 1997.

CANTON, Kátia. Novíssima Arte Brasileira - um guia de tendências. São Paulo: Iluminuras Ltda., 2001. . Espelho de Artista. São Paulo: Cosac \& Naify Edições, 2001.

DOMINGUES, Diana. A Arte no Século XXI. A humanização das tecnologias. São Paulo: Unesp, 1997.

. Arte e Tecnologia. In: II Bienal Mercosul: arte e tecnologia. Porto Alegre: Fundação Bienal de Arte Visuais do Mercosul, 2000.

FARIAS, Agnaldo. Arte Brasileira Hoje. São Paulo: Publifolha, 2002.

. Tem de tudo, mas não vale tudo. In: Revista Aplauso. Porto Alegre: v. 58, ano 7, p. 14, 2005.

HALL, Stuart. A identidade cultural na pós-modernidade. Rio de Janeiro: DP\&A, 2003.

HARVEY, David. Condição Pós-Moderna: uma pesquisa sobre as origens da mudança cultural. São Paulo: Loyola, 1992.

HEARTNEY, Eleanor. Pós-modernismo. São Paulo: Cosac \& Naify, 2002.

JUSTINO, Maria José. Seja Marginal, Seja Herói: Modernidade e Pós-modernidade em Hélio Oiticica. Curitiba: UFPR, 1998.

LYOTARD, Jean-François. A Condição Pós-Moderna. Rio de Janeiro: José Olympio, 2002.

PEREIRA,Otaviano.www.uniube.br/institucional/proreitoria/propep/mestrado/educacao/

revista/vol03/07/otaviano.htm

RIEMSCHNEIDER, Burkhard, GROSENICK, Uta. Arte Actual. Taschen, s/d.

SANTOS, Jair Ferreira. O Que é Pós-Moderno. São Paulo: Brasiliense, 2004.

SILVA, Tomaz Tadeu da: O Currículo como Fetiche: a poética do texto curricular. Belo Horizonte: Autêntica, 2003. 